\title{
Preparation and characterization of isotropic pitch-based carbon fiber
}

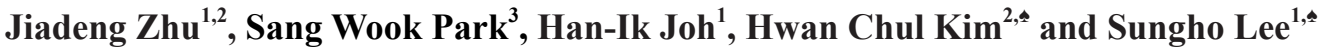 \\ ${ }^{1}$ Carbon Convergence Materials Research Center, Institute of Advanced Composite Materials, Korea Institute of Science and Technology, \\ Wanju 565-905, Korea \\ ${ }^{2}$ Department of Organic Materials and Fiber Engineering, Chonbuk National University, Jeonju 561-756, Korea \\ ${ }^{3}$ Chemical and Polymer Laboratory, GS Caltex R\&D Center, Daejeon 305-380, Korea
}

\section{Article Info}

Received 10 March 2013

Accepted 5 April 2013

*Corresponding Author

E-mail: hckim@jbnu.ac.kr sunghol@kist.re.kr

\section{Open Access}

DOI: http://dx.doi.org/

$$
\text { 10.5714/CL.2013.14.2.094 }
$$

This is an Open Access article distributed under the terms of the Creative Commons Attribution Non-Commercial License (http://creativecommons.org/licenses/ by-nc/3.0/) which permits unrestricted non-commercial use, distribution, and reproduction in any medium, provided the original work is properly cited.

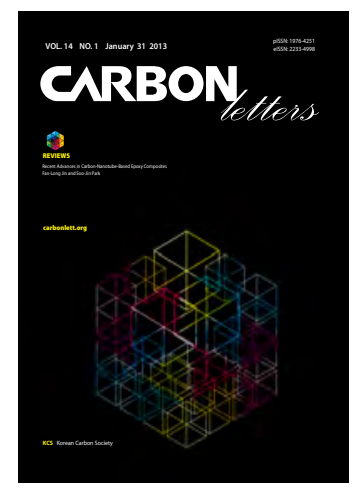

http://carbonlett.org

pISSN: 1976-4251

elSSN: 2233-4998

Copyright $\odot$ Korean Carbon Society

\begin{abstract}
Isotropic pitch fibers were stabilized and carbonized for preparing carbon fibers. To optimize the duration and temperature during the stabilization process, a thermogravimetric analysis was conducted. Stabilized fibers were carbonized at 1000,1500 , and $2000^{\circ} \mathrm{C}$ in a furnace under a nitrogen atmosphere. An elemental analysis confirmed that the carbon content increased with an increase in the carbonization temperature. Although short graphitic-like layers were observed with carbon fibers heat-treated at 1500 and $2000^{\circ} \mathrm{C}$, Raman spectroscopy and X-ray diffraction revealed no significant effect of the carbonization temperature on the crystalline structure of the carbon fibers, indicating the limit of developing an ordered structure of isotropic pitch-based carbon fibers. The electrical conductivity of the carbonized fiber reached $3.9 \times 10^{4} \mathrm{~S} / \mathrm{m}$ with the carbonization temperature increasing to $2000^{\circ} \mathrm{C}$ using a four-point method.
\end{abstract}

Key words: isotropic pitch, stabilization, carbonization, Raman, X-ray diffraction

\section{Introduction}

Carbon fiber (CF) is considered to be a useful reinforcement for composites due to its excellent properties, such as its high modulus, dimensional stability, and excellent thermal and electrical conductivities [1-5]. Therefore, CF has received a considerable amount of attention in variety of specialized applications in the fields of sporting goods, aircraft, aerospace, wind energy, and in the automotive industry [6]. CF can be classified into three types depending on the precursor: polyacrylonitrile-based CF, rayon-based CF and pitch-based CF. Pitch-based $\mathrm{CFs}$ can be further classified into two types. One is high-performance CF from mesophase pitch, which exhibits liquid crystalline behavior and requires a process which converts coal tar or petroleum residue oil to mesophase-grade pitch. The processes described in the literature for obtaining mesophase pitch include the polymerization of aromatic hydrocarbons using aluminum chloride as a catalyst [7], the supercritical fluid extraction of petroleum pitch [8], and high-temperature centrifugation [9]. The other type is general purpose CF from isotropic pitch, which shows more modest properties [10,11]. However, isotropic pitch is an attractive precursor for $\mathrm{CF}$, as it can be manufactured at a reasonable cost.

It is well known that the stabilization process plays an extremely important role in manufacturing $\mathrm{CF}$ [12]. As-spun pitch fibers require an additional treatment to make them suitable for subsequent carbonization. Isotropic pitch has a lower degree of condensation, a high hydrogen content and a lower softening point, all of which result in more 
time needed to form an oxygen bridge structure via oxidation, dehydrogenation, cross-linking and cyclization during a stabilization process, where small molecules such as $\mathrm{H}_{2} \mathrm{O}, \mathrm{CO}$, and $\mathrm{CO}_{2}$ can be evaporated $[12,13]$. However, over-oxidation will produce a brittle product with poor tensile properties due to the formation of quinones, which can produce $\mathrm{CO}$ during the heat treatment [13].

In this work, stabilization and carbonization of melt-spun isotropic pitch fibers are studied. The thermal behavior of pitch fibers during the stabilization process is observed by thermal gravimetric analysis (TGA). Subsequently, stabilized fibers are carbonized at temperatures of 1000,1500 , and $2000^{\circ} \mathrm{C}$. After the carbonization step, Raman spectroscopy, X-ray diffraction (XRD), and transmission electron microscopy (TEM) are used to observe the effect of the carbonization temperature on the structural evolution of CFs.

\section{Experimental}

\subsection{Materials}

Synthesized pitch was prepared from naphtha cracking bottom oil by a halogen-derived polymerization procedure consisting of the bromination of raw material, debrominated condensation and subsequent thermal treatment/distillation [14]. A thermal treatment with distillation was adjusted until the desired softening point was reached $\left(\sim 268^{\circ} \mathrm{C}\right)$. Pitch fibers were prepared using the resulting isotropic pitch as a precursor. The pitch was melt-spun in a stainless steel barrel, and the diameters of the spinneret and winder were $500 \mu \mathrm{m}$ and $260 \mathrm{~mm}$, respectively. The spinning temperatures were 300 to $310^{\circ} \mathrm{C}$, which were 30 to $40^{\circ} \mathrm{C}$ above the softening point of the pitch. Once the spinning temperature was optimized, extrusion pressure of 5 bar with nitrogen at a winding speed of $300 \mathrm{rpm}$ was used to obtain pitch fibers.

\subsection{Preparation of the pitch-based CF}

The as-spun fibers were stabilized at $270^{\circ} \mathrm{C}$ for $2 \mathrm{~h}$ under an air atmosphere in a convection oven. After stabilization, the fibers were carbonized at 1000,1500 , and $2000^{\circ} \mathrm{C}$ under a nitrogen atmosphere at a heating rate of $5^{\circ} \mathrm{C} / \mathrm{min}$ in a furnace. The heat-treated fibers naturally cooled down to room temperature after they reached the maximum temperature.

\subsection{Characterizations}

TGA was used to obtain the optimum stabilization temperature and time in an air atmosphere with a heating rate of $5^{\circ} \mathrm{C} / \mathrm{min}$ using a TGA Q50 (TA instruments, USA). After reaching a certain temperature, samples were held at least 8 h. The weight of each sample used for the test was approximately $10 \mathrm{mg}$.

Raman spectroscopy was performed using a Raman spectrometer with a power of $16 \mathrm{~mW}$ and a $633 \mathrm{~nm}$ diode laser (Horiba Jobin Yvon, France). Spectra were obtained with a range from 500 to $3500 \mathrm{~cm}^{-1}$ in continuous scanning mode. The XRD patterns of all samples were obtained using a X-ray dif- fractometer (D/MAX 2500, Rigaku) with $\mathrm{Cu} \mathrm{K} \alpha$ radiation $(\lambda=$ $0.15418 \mathrm{~nm}$ ) to analyze the crystalline structure of the CFs and calculate the interlayer spacing. XRD was operated at a voltage of $40 \mathrm{kV}$ and an emission current of $50 \mathrm{~mA}$ with a scanning speed $2 \%$ min. The interlayer spacing $\left(d_{002}\right)$ was calculated by Bragg's law,

$$
d_{002}=\lambda / 2 \sin \theta,
$$

where $\lambda$ is the wavelength of the radiation, $\theta$ is the Bragg angle [15].

TEM (JEM2200FS, USA) was carried out at an accelerating voltage of $200 \mathrm{kV}$ to observe the graphitic structure of the CFs. The CFs were embedded in epoxy resin and then microtomed with a thickness of less than $100 \mathrm{~nm}$. Samples were collected on a carbon grid to be observed by TEM. Field-emission scanning electron microcopy (FE-SEM, Hitachi S-4700) was performed at an acceleration voltage of $10 \mathrm{kV}$ to examine the cross-sections of the samples. An average diameter of the CFs was obtained from at least twenty SEM micrographs. Elemental analysis (Flash EA 1112 series, Thermo Fisher Scientific) was carried out in order to determine the effect of the carbonization temperature on the amounts of $\mathrm{C}, \mathrm{H}, \mathrm{N}, \mathrm{O}$ and $\mathrm{S}$. A four-probe point method was used to measure the electrical conductivity of a single fiber with a resistivity meter (FPP-RS8, Dasol Eng., Korea). The average taken from five samples was reported, and T-300, a commercial PAN-based CF, was utilized as a reference to confirm the accuracy of the measurement.

\section{Results and Discussion}

\subsection{TGA}

Fig. 1 shows TGA thermograms of the as-spun fibers at various holding temperatures. The weight of the samples increased with an increase in the heating time, and a temperature of $270^{\circ} \mathrm{C}$ led to the highest weight gain $(\sim 8.8 \mathrm{wt} \%)$ due to oxidation. This crosslinking reaction helped the fibers maintain their shape, allowing them to be carbonized in the following process

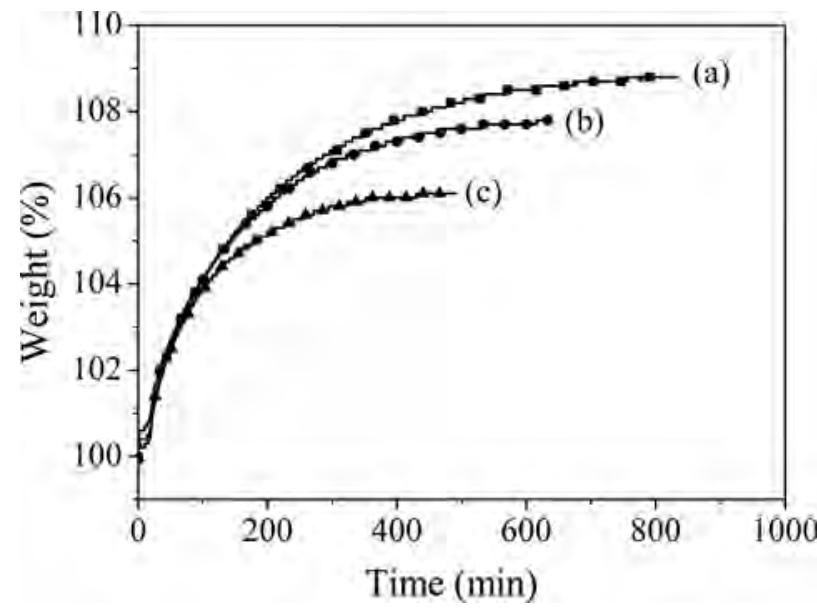

Fig. 1. Thermal gravimetric analysis thermograms of as-spun fiber treated at various temperatures under air: (a) 270 , (b) 280 , and (c) $290^{\circ} \mathrm{C}$. 


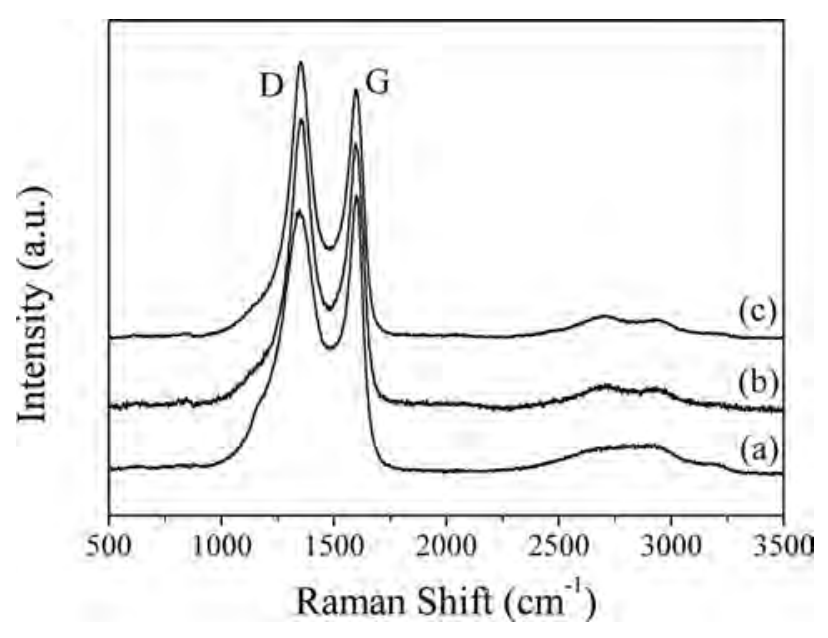

Fig. 2. Raman spectra of carbon fibers at various carbonization temperatures: (a) 1000 , (b) 1500 , and (c) $2000^{\circ} \mathrm{C}$.

without inter-filament fusing. From Fig. 1, the rates of increase of the weight of the as-spun fibers stabilized at 280 and 290 were lower than those at $270^{\circ} \mathrm{C}$ due to differences between the amount of oxygen uptake and the evaporation of materials with low boiling points. Therefore, the weights gained by fibers tested at 280 or $290^{\circ} \mathrm{C}$ for the given times were lower than the gains by the fibers tested at $270^{\circ} \mathrm{C}$. Because stabilization is one of the most costly steps when producing $\mathrm{CF}$, it is necessary to reduce the time for stabilization [16]. As noted by Stevens and Diefendrof [17], a typical mesophase fiber requires an increase of $6 \%$ in its mass for adequate stabilization. Therefore, from the TGA results, the as-spun fibers were stabilized in a convection oven at $270^{\circ} \mathrm{C}$ for $2 \mathrm{~h}$. The resulting fibers were carbonized at 1000,1500 , and $2000^{\circ} \mathrm{C}$ in a furnace under a $\mathrm{N}_{2}$ atmosphere.

\subsection{Raman}

Raman spectroscopy has been confirmed to be a powerful method for characterizing carbonaceous materials [18-20]. The Raman spectra of CFs with various carbonization temperatures are shown in Fig. 2. For all CFs, the spectra showed two characteristic bands around 1356 and $1599 \mathrm{~cm}^{-1}$, termed the D and G band, respectively. The $\mathrm{D}$ band stems from the disordered structures or defects in the carbon, and the $\mathrm{G}$ band is associated with tangential stretching vibrations of the $\mathrm{C}-\mathrm{C}$ bonds $[21,22]$. Even with $\mathrm{CF}$ heat-treated at $2000^{\circ} \mathrm{C}$, a broad $\mathrm{D}$ band was distinct, indicating that the $\mathrm{CF}$ had a disordered structure, which could also be observed from the XRD diffractograms.

\subsection{XRD}

Fig. 3 shows XRD diffractograms of CFs at different temperatures. Two peaks were obvious regardless of the carbonization temperature. The former diffraction peak corresponded to the (002) reflection of the pseudo-graphite structure. According to Bragg's law, the interlayer spacing of CFs, whose $2 \theta$ values were 23.1 and $23.9^{\circ}$ corresponding to a carbonization temperature of 1000 and $1500^{\circ} \mathrm{C}$, respectively, decreased from 0.384 to

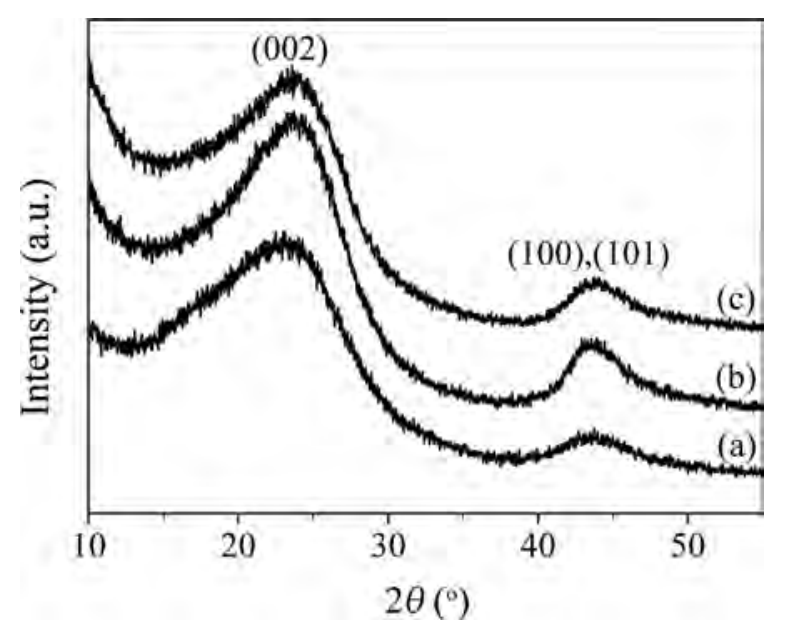

Fig. 3. X-ray diffractograms of carbon fibers at various carbonization temperatures: (a) $1000,(b) 1500$, and (c) $2000^{\circ} \mathrm{C}$.

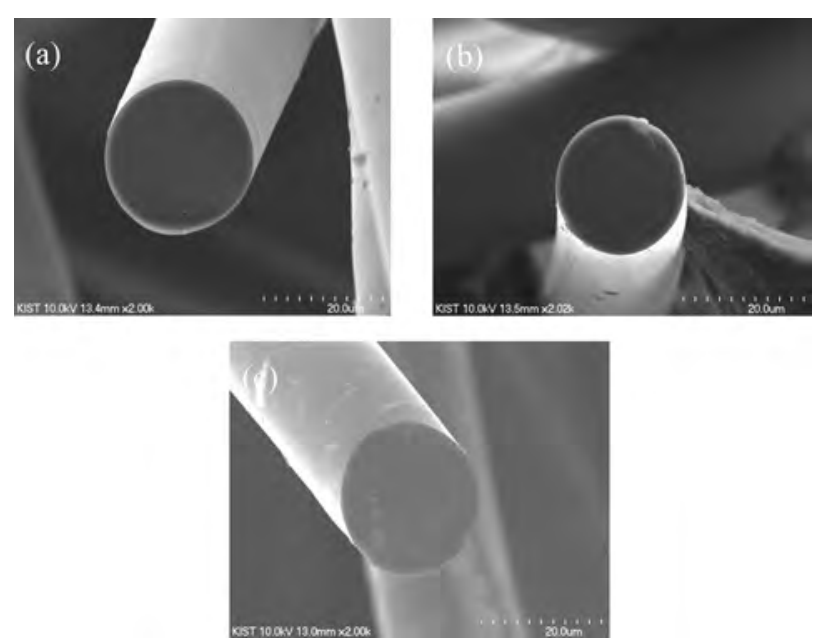

Fig. 4. Scanning electron microscopy images of carbon fibers at various carbonization temperatures: (a) 1000 , (b) 1500 , and (c) $2000^{\circ} \mathrm{C}$.

$0.373 \mathrm{~nm}$ due to the structural development. However, there was no further change as the carbonization temperature increased to $2000^{\circ} \mathrm{C}$, which is related to the low degree of crystallinity of the CFs. The latter one showed a combination of (100) and (101) planes, which are usually assigned to the turbostratic bands of disordered carbon materials [23].

\subsection{SEM}

SEM images of CFs are shown in Fig. 4. Each shows a smooth texture, which differs from the typical radial texture of anisotropic pitch-based CFs [24]. The diameter of each CF is summarized in Table 1. As expected, diameters of the CFs decreased with an increase in the carbonization temperature. The diameters of the CFs decreased from 24.8 to $19.2 \mu \mathrm{m}$ as the carbonization temperature increased from 1000 to $2000^{\circ} \mathrm{C}$ because hetero-atoms of $\mathrm{H}, \mathrm{N}$, and $\mathrm{O}$ were released and because structure was developed during the carbonization process [25]. However, a significant microstructure was not observed in the SEM images of the CFs independent of the carbonization conditions. 
Table 1. Diameters and electrical conductivities of carbon fibers at various carbonization temperatures

\begin{tabular}{cccc}
$\begin{array}{c}\text { Carbonization } \\
\text { temperature }\left({ }^{\circ} \mathrm{C}\right)\end{array}$ & 1000 & 1500 & 2000 \\
\hline $\begin{array}{c}\text { Diameter }(\mu \mathrm{m}) \\
\begin{array}{c}\text { Electrical conductivity } \\
(\mathrm{S} / \mathrm{m})\end{array}\end{array}$ & 24.8 & 21.7 & 19.2 \\
\hline
\end{tabular}

T-300: measurement $=3.9 \times 10^{4} \mathrm{~S} / \mathrm{m}$, Ref. $=5.6 \times 10^{4} \mathrm{~S} / \mathrm{m}$.
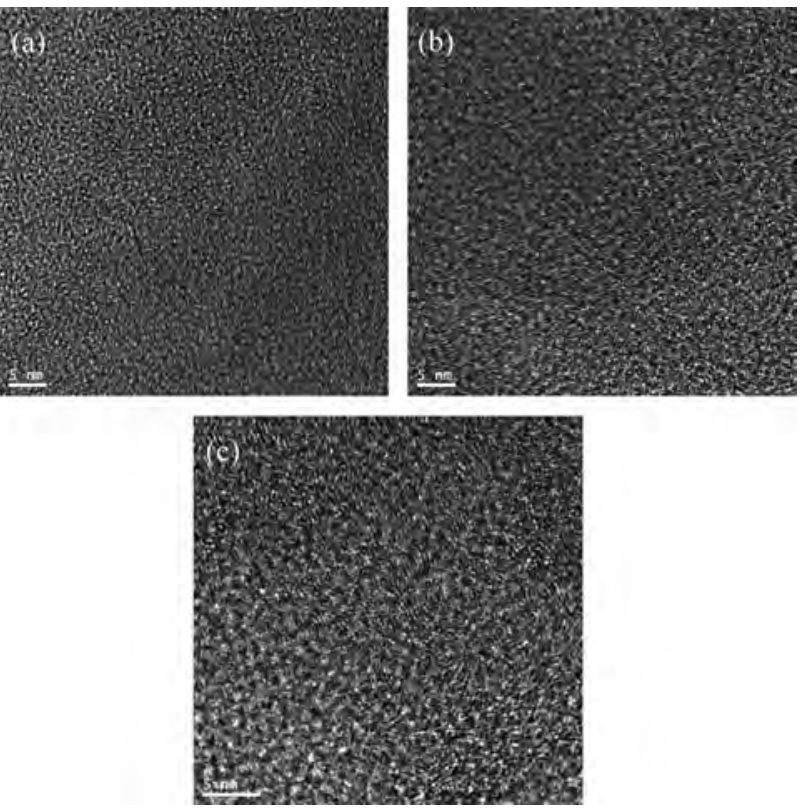

Fig. 5. Transmission electron microscopy images of carbon fibers at various carbonization temperatures: (a) 1000 , (b) 1500 , and (c) $2000^{\circ} \mathrm{C}$.

\subsection{TEM}

TEM micrographs of CFs processed at a carbonization temperature of 1000,1500 , and $2000^{\circ} \mathrm{C}$ are displayed in Figs. 5a-c, respectively, to observe their structures. Upon a heat-treatment temperature at $1000^{\circ} \mathrm{C}$, two to three layers of distorted columns approximately $2 \mathrm{~nm}$ long are shown in Fig. 5a. In Fig. $5 \mathrm{~b}$, the number of the layers is increased to nearly 10 and the length of the column increased to $10 \mathrm{~nm}$ with a heat-treatment temperature of $1500^{\circ} \mathrm{C}$ as they became more aligned [26,27]. However, there was no clear change in the structure when the heat-treatment temperature of $2000^{\circ} \mathrm{C}$ due to the structural development limit. This was in good agreement with the Raman and XRD results.

\subsection{Electrical conductivity}

The electrical conductivities of the CFs are displayed in Table 1. As shown in Table 1, there was no notable difference between the measurement value of T-300 (Toray, Japan) and the value provided by the manufacturer, which confirmed the accuracy of the measurement. The conductivity of CF increased from 4.8 $\times 10^{3}$ to $2.4 \times 10^{4} \mathrm{~S} / \mathrm{m}$ with an increase in the carbonization temperature from 1000 to $1500^{\circ} \mathrm{C}$ due to the development of
Table 2. Element analysis of carbon fibers at various carbonization temperatures

\begin{tabular}{cccc}
\multirow{2}{*}{ Element } & \multicolumn{3}{c}{ Weight percentage $(\mathrm{wt} \%)$} \\
\cline { 2 - 4 } & $1000^{\circ} \mathrm{C}$ & $1500^{\circ} \mathrm{C}$ & $2000^{\circ} \mathrm{C}$ \\
\hline $\mathrm{N}$ & 0.2 & 0.1 & 0.1 \\
$\mathrm{C}$ & 90.4 & 97.1 & 99.1 \\
$\mathrm{H}$ & 0.2 & 0 & 0 \\
$\mathrm{O}$ & 9.2 & 2.8 & 0.8 \\
$\mathrm{~S}$ & 0 & 0 & 0 \\
\hline
\end{tabular}

the structure to facilitate the movement of electrons, as also observed in the TEM images. The electrical conductivity of the sample carbonized at a high temperature of $2000^{\circ} \mathrm{C}$ was $3.9 \times$ $10^{4} \mathrm{~S} / \mathrm{m}$, which was similar to the result at $1500^{\circ} \mathrm{C}$ owing to the structural development limit.

\subsection{Element analysis}

The results of the element analysis corresponding to different carbonization temperatures are shown in Table 2. It was obvious that the concentrations of oxygen, nitrogen and hydrogen decreased with an increase in the carbonization temperature, as hetero-atoms were continuously released to form a turbostratic structure [28]. There was already no sulfur left when the carbonization temperature was $1000^{\circ} \mathrm{C}$, indicating that sulfur may be removed in the form of $\mathrm{SO}_{2}$ at an early stage of carbonization [13]. Hydrogen and nitrogen were assumed to be removed primarily in the forms of $\mathrm{N}_{2}, \mathrm{H}_{2} \mathrm{O}, \mathrm{H}_{2}$ and low-molecular alkanes during the carbonization process $[13,29]$. The concentration of oxygen significantly decreased from 9.2 to $2.8 \mathrm{wt} \%$ when the heat-treatment temperature increased to $1500^{\circ} \mathrm{C}$ due to the continuous evaporation of $\mathrm{H}_{2} \mathrm{O}, \mathrm{CO}_{2}$, and $\mathrm{CO}$. Over $1500^{\circ} \mathrm{C}$, it was assumed that oxygen was also released in the form of $\mathrm{O}_{2}$ in addition to the above cases [13]. Finally, the carbon concentration reached 99.1 $\mathrm{wt} \%$ when the carbonization temperature reached $2000^{\circ} \mathrm{C}$.

\section{Conclusions}

Isotropic pitch-based CFs were obtained via a stabilization and carbonization process. TGA was used to observe weight changes during the stabilization of the as-spun fibers. The graphitic-like structure of CFs was studied by Raman spectroscopy and XRD. In the Raman spectra, broad D and G bands were observed regardless of the carbonization temperature. (002), (100), and (101) diffraction peaks in the XRD diffractograms were assigned to the turbostratic disordered structure. The (002) peak was broad with $\mathrm{CF}$ heat-treated at $2000^{\circ} \mathrm{C}$ due to the low degree of crystallinity. The electrical conductivities of the CFs increased with an increase in the carbonization temperature. The values were found to range from $4.8 \times 10^{3}$ to $2.4 \times 10^{4} \mathrm{~S} / \mathrm{m}$ at carbonization temperatures of 1000 to $1500^{\circ} \mathrm{C}$. However, there was no significant difference in the electrical conductivity with a further increase in the carbonization temperature due to structural development limits, as observed by TEM. 


\section{Acknowledgements}

This work was supported by a grant from the Korea Institute of Science and Technology Institutional program and by the Carbon Valley project funded by the Ministry of Knowledge Economy, Republic of Korea.

\section{References}

[1] Northolt MG, Veldhuizen LH, Jansen H. Tensile deformation of carbon fibers and the relationship with the modulus for shear between the basal planes. Carbon, 29, 1267 (1991). http://dx.doi. org/10.1016/0008-6223(91)90046-L.

[2] Kumar S, Anderson DP, Crasto AS. Carbon fibre compressive strength and its dependence on structure and morphology. J Mater Sci, 28, 423 (1993). http://dx.doi.org/10.1007/BF00357820.

[3] Edie DD, Fain CC, Robinson KE, Harper AM, Rogers DK. Ribbon-shape carbon fibers for thermal management. Carbon, 31, 941 (1993). http://dx.doi.org/10.1016/0008-6223(93)90196-H.

[4] Hong SH, Korai Y, Mochida I. Development of mesoscopic textures in transverse cross-section of mesophase pitch-based carbon fibers. Carbon, 37, 917 (1999). http://dx.doi.org/10.1016/S00086223(98)00236-X.

[5] Hong SH, Korai Y, Mochida I. Mesoscopic texture at the skin area of mesophase pitch-based carbon fiber. Carbon, 38, 805 (2000). http://dx.doi.org/10.1016/S0008-6223(99)00175-X.

[6] Edie DD. The effect of processing on the structure and properties of carbon fibers. Carbon, 36, 345 (1988). http://dx.doi.org/10.1016/ S0008-6223(97)00185-1.

[7] Mochida I, Kudo K, Fukuda N, Takeshita K. Carbonization of pitches--IV: Carbonization of polycyclic aromatic hydrocarbons under the presence of aluminum chloride catalyst. Carbon, 13, 135 (1975). http://dx.doi.org/10.1016/0008-6223(75)90270-5.

[8] Hutchenson KW, Roebers JR, Thies MC. Fractionation of petroleum pitch by supercritical fluid extraction. Carbon, 29, 215 (1991). http://dx.doi.org/10.1016/0008-6223(91)90072-Q

[9] Kim CJ, Ryu SK, Rhee BS. Properties of coal tar pitch-based mesophase separated by high-temperature centrifugation. Carbon, $\mathbf{3 1}$ 833 (1993). http://dx.doi.org/10.1016/0008-6223(93)90023-4.

[10] Wazir AH, Kakakhel L. Preparation and characterization of pitchbased carbon fibers. New Carbon Mater, 24, 83 (2009). http:// dx.doi.org/10.1016/S1872-5805(08)60039-6.

[11] Mora E, C. Blanco C, Prada V, Santamaria R, Granda M, Menendez R. A study of pitch-based precursors for general purpose carbon fibres. Carbon, 40, 2719 (2002). http://dx.doi.org/10.1016/ S0008-6223(02)00185-9.

[12] Miuea K, Nakagawa H, Hashimoto K. Examination of the oxidative stabilization reaction of the pitch-based carbon fiber through continuous measurement of oxygen chemisorption and gas formation rate. Carbon, 33, 275 (1995). http://dx.doi.org/10.1016/00086223(94)00133-K.

[13] Morgan P. Carbon fibers and their composites, Taylor \& Francis, Boca Raton, 296 (2005)

[14] Dongbu Hannong Chem. Production of high-softening optically isotropic pitch. KR Patent, 1999-0012608 (1999).

[15] Liu S, Blanco C, Rand B. Large diameter carbon fibres from mesophase pitch. Carbon, 40, 2109 (2002). http://dx.doi.org/10.1016/ S0008-6223(02)00060-X.

[16] Hayashi JI, Nakashima M, Kusakabe K, Morooka S, Mitsuda S. Rapid stabilization of pitch precursor by multi-step thermal oxidation. Carbon, 33, 1567 (1995). http://dx.doi.org/10.1016/00086223(95)00118-W.

[17] Stevens WC, Diefendorf RJ. Thermosetting of mesophase pitches: experimental. Carbon '86: Proceedings of the 4th International Conference on Carbon, Baden-Baden, Germany, 37 (1986).

[18] Li DF, Wang HJ, Wang XK. Effect of microstructure on the modulus of PAN-based carbon fibers during high temperature treatment and hot stretching graphitization. J Mater Sci, 42, 4642 (2007). http://dx.doi.org/10.1007/s10853-006-0519-4.

[19] Tuinstra F, Koenig JL. Raman spectrum of graphite. J Chem Phys, 53, 1126 (1970). http://dx.doi.org/10.1063/1.1674108.

[20] Melanitis N, Tetlow PL, Galiotis C. Characterization of PAN-based carbon fibres with laser Raman spectroscopy. J Mater Sci, 31, 851 (1996). http://dx.doi.org/10.1007/BF00352882.

[21] Jin XD, Ni QQ, Fu YQ, Zhang L, Natsuki T. Electrospun nanocomposite polyacrylonitrile fibers containing carbon nanotubes and cobalt ferrite. Polym Compos, 33, 317 (2012). http://dx.doi. org/10.1002/pc. 21251 .

[22] McNally T, Potschke P, Halley P, Murphy M, Martin D, Bell SEJ, Brennan GP, Bein D, Lemoine P, Quinn JP. Polyethylene multiwalled carbon nanotube composites. Polymer, 46, 8222 (2005). http://dx.doi.org/10.1016/j.polymer.2005.06.094.

[23] Dong ZJ, Li XK, Yuan GM, Cui ZW, Cong Y, Westwood A. Synthesis in molten salts and formation reaction kinetics of tantalum carbide coatings on various carbon fibers. Surf Coat Technol, 212, 169 (2012). http://dx.doi.org/10.1016/j.surfcoat.2012.09.040.

[24] Watanabe F, Ishida S, Korai Y, Mochida I, Kato I, Sakai Y, Kamatsu M. Pitch-based carbon fiber of high compressive strength prepared from synthetic isotropic pitch containing mesophase spheres. Carbon, 37, 961 (1999). http://dx.doi.org/10.1016/S00086223(98)00251-6.

[25] Diez N, Alvarez P, Santamaria R, Blanco C, Menendez R, Granda M. Optimisation of the melt-spinning of anthracene oil-based pitch for isotropic carbon fibre preparation. Fuel Process Technol, 93, 99 (2012). http://dx.doi.org/10.1016/j.fuproc.2011.09.016.

[26] Guigon M, Oberlin A, Desarmot G. Microtexture and structure of some high tensile strength, PAN-based carbon fibres. Fibre Sci Technol, 20, 55 (1984). http://dx.doi.org/10.1016/0015-0568 (84)90057-5.

[27] Guigon M, Oberlin A, Desarmot G. Microtexture and structure of some high-modulus, PAN-based carbon fibres. Fibre Sci Technol, 20, 177 (1984). http://dx.doi.org/10.1016/0015-0568(84)90040-X.

[28] Bright AA, Singer LS. The electronic and structural characteristics of carbon fibers from mesophase pitch. Carbon, 17, 59 (1979). http://dx.doi.org/10.1016/0008-6223(79)90071-X.

[29] Dumont M, Dourges MA, Bourrat X, Pailler R, Naslain R, Babot O, Birot M, Pillot JP. Carbonization behavior of modified synthetic mesophase pitches. Carbon, 43, 2277 (2005). http://dx.doi. org/10.1016/j.carbon.2005.04.007. 